\title{
Arranjo institucional, capacidades estatais e política industrial: os Conselhos de Competitividade do Plano Brasil Maior
}

\author{
Guilherme de Queiroz Stein \\ Mestre em Ciência Política (Universidade Federal do Rio Grande do Sul) \\ Porto Alegre, Brasil \\ guiqstein@yahoo.com.br \\ Alfredo Alejandro Gugliano \\ Doutor em Ciências Políticas e Sociologia \\ (Universidad Complutense de Madrid) \\ Professor Adjunto da Universidade Federal do Rio Grande do Sul \\ Porto Alegre, Brasil \\ alfredogugliano@hotmail.com
}

Resumo

Nesse artigo discute-se a relação entre capacidades estatais e política industrial a partir da perspectiva de análise de arranjos institucionais de políticas públicas. Como objeto empírico, analisa-se a experiência histórica da implementação de conselhos setoriais tripartites na política industrial brasileira e o caso dos Conselhos de Competitividade do Plano Brasil Maior. As conclusões apontam que os Conselhos de Competitividade reproduziram problemas encontrados nas experiências prévias e foram incapazes de gerar capacidades suficientes para coordenar os atores da maneira como sua função exigia.

Palavras-chave: capacidades estatais, arranjos institucionais, políticas públicas, política industrial, conselhos setoriais tripartites.

\section{Introdução}

No presente artigo discute-se a relação entre capacidades estatais e política industrial, com especial atenção ao que vem se denominando capacidades políticas. Essa variante do conceito de capacidades estatais tem sido aplicada na agenda de pesquisas que se propõe a estudar 
os arranjos institucionais de políticas públicas no atual contexto democrático brasileiro (Gomide; Pires, 2014).

O conceito de arranjos institucionais de políticas públicas busca dar conta das regras que mediam as relações e as transações entre os agentes participantes de uma política pública, de modo a coordená-los, determinar quem participa e quem é excluído dos processos, formular objetivos e linhas de ação e, concretamente, executar as diretrizes estabelecidas. Já o conceito de capacidades políticas diz respeito à necessidade de, em contextos democráticos, se formular objetivos relativamente consensuais e viabilizar a implementação de determinadas políticas, coordenar interesses de modo a mitigar conflitos, canalizar informações necessárias à formulação, formular visões de futuro compartilhadas, construir bases de legitimidade para as políticas e atuar de maneira responsiva aos interesses da sociedade civil. Outro aspecto fundamental é dar conta do accountability horizontal, dada a necessária interação entre o poder Executivo e o poder Legislativo, a atuação de instituições de controle (judiciário, tribunais de conta, Ministério Público, órgãos investigativos) e promoção de ações transparentes frente à sociedade como um todo (Gomide; Pires, 2014).

Assim, o conceito de capacidades políticas pode ser segmentado em três dimensões. A primeira é a dimensão participativa, a qual leva em conta as relações diretas entre governo e sociedade civil. A segunda é chamada dimensão representativa, essa analisa as relações entre executivo e legislativo. A terceira é a dimensão do controle legal, que observa os mecanismos e as relações que se estabelecem em uma política pública no que se refere às questões judiciais e às instituições de controle Gomide; Pires, 2014).

Nesse trabalho, nos preocupamos com a dimensão participativa das capacidades políticas, a qual se refere às relações diretas entre atores governamentais e agentes representantes da sociedade civil interessados na política. No caso específico da política industrial, foca-se na interlocução entre governo, empresários e trabalhadores, em arenas formais de diálogo e negociação.

Em estudo anterior sobre as arenas tripartites que constituíram a estrutura de governança das políticas industriais lançadas entre 2003 e 2014 (Queiroz-Stein, 2016), observou-se que, no início desse período, para retomar a implantação de políticas industriais, o Governo Federal buscou estruturar essas capacidades políticas constituindo o Conselho de Desenvolvimento Econômico e Social da Presidência da República (CDES) e o Conselho Nacional de Desenvolvimento Industrial (CNDI). Assim, entre 2003 e 2007, esses espaços foram fundamentais na construção de capacidades políticas, as quais se encontravam subjacentes ao desenvolvimento de uma política industrial que apresentou bons resultados (De Toni, 2015).

Contudo, a partir de 2007 essas capacidades começam a ser perdidas, fato que se expressa claramente na desativação do CNDI. Essa perda é acentuada a partir de 2011, quando o funcionamento do CDES passa a ser precário e a tentativa de reativar o CNDI fracassa. Apesar disso, entre 2011 a 2014, quando estava em vigor o Plano Brasil Maior (PBM), na estrutura de governança da política industrial previu-se a criação de 19 novas 
arenas, com a função de deliberar e aconselhar sobre políticas voltadas a setores econômicos específicos, as quais foram denominadas Conselhos de Competitividade. Essas arenas setoriais tripartites retomavam um modelo de governança da política industrial inaugurado ainda na década de 1990, o que na época se denominou câmaras setoriais. Nesse período, a experiência com as câmaras setoriais foi bastante emblemática por ter se verificado alguns casos de rápido sucesso em se propor políticas industriais que efetivamente promoveram a geração de empregos e o aumento da competitividade.Todavia, não faltaram também casos de fracassos em número suficientes para se difundir uma descrença quanto aos potenciais desses espaços. De todo modo, em praticamente todas as políticas industriais apresentadas pelos governos, desde o início da década de 1990, verificou-se alguma forma semelhante de estrutura de governança.

Tendo em vista essas considerações, nesse artigo, propõe-se investigar se nos Conselhos de Competitividades do PBM foram verificadas inovações capazes de estruturar novas capacidades políticas para o arranjo institucional da política industrial do Governo Federal.Também, analisou-se se essas capacidades foram capazes de compensar a perda de capacidades políticas, verificada desde 2007.

Para operacionalizar esse estudo, foram analisadas as atas das reuniões e o estatuto do PBM que regia o funcionamento dos Conselhos de Competitividade. A partir dessas informações, buscou-se quantificar algumas variáveis-chave, como o número de reuniões, o número de participantes e os percentuais da participação de cada segmento (trabalhadores, empresários, governo). Essas variáveis foram usadas para analisar a institucionalização, a adesão governamental e a adesão da sociedade civil aos conselhos. Ainda, foi necessário observar quais eram os atores mais ativos em cada segmento, qual seu vínculo institucional e, no caso da sociedade civil, quem suas organizações representavam. Assim, buscou-se dar conta de elementos-chave para o funcionamento desses espaços como a presença de altos-escalões governamentais e a representatividade dos conselheiros não-governamentais. A leitura das atas também possibilitou fazer inferências sobre a troca informacional e a coordenação dos agentes, especialmente em como isso se refletia em medidas efetivas. Para tanto, essa avaliação foi feita observando as deliberações dos conselhos estudados e a inclusão de suas propostas nas Agendas Estratégicas Setoriais formuladas no período ${ }^{1}$.

Para dar conta dessas questões, o artigo apresenta quatro seções. Além dessa introdução, numa primeira seção realiza-se uma discussão sobre o conceito de capacidades estatais e sua importância para a análise de políticas industriais, com especial atenção ao papel das capacidades políticas. Na segunda parte, apresenta-se a experiência histórica das arenas setoriais tripartites, baseando-se em revisão de estudos empíricos sobre essas experiências, de modo a estabelecer um parâmetro para a comparação histórica. Na terceira parte, analisam-se as capacidades políticas dos Conselhos de Competitividade do PBM. Nessa parte, investiga-se em profundidade a constituição dessas capacidades no Conselho de Competitividade da Indústria de Defesa, Aeronáutica e Espacial e no Conselho de

1 Para uma discussão mais aprofundada de indicadores de capacidade política para a análise da participação em políticas industriais, ver Queiroz-Stein (2017). 
Competitividade da Indústria Química.A escolha desses casos foi feita levando em conta a disponibilidade de dados, o potencial tecnológico, a frequência e a distribuição ao longo do tempo das reuniões. Por fim, nas considerações finais, realiza-se uma síntese das análises desenvolvidas, tendo em vista responder as questões debatidas.

\section{Capacidades estatais e política industrial}

Atualmente, o conceito de capacidades estatais abarca múltiplas dimensões, em função de ter incorporado concepções teóricas diversas na tentativa de melhor precisá-lo. Para alguns, é uma noção inacabada, uma "criatura desajeitada" (clumsy creature), um campo a ser definido (Cingolani, 2013). Porém, é flexível de modo que permite explorar diferentes aspectos da ação estatal e da relação das estruturas estatais com a sociedade e com o sistema econômico.

Mesmo aceitando a sua utilização para o estudo do desenvolvimento dos Estados nas sociedades contemporâneas, é preciso ponderar vantagens e desvantagens desse conceito. De um lado, um dos problemas do conceito é que ele não pode ser utilizado de forma linear, isto é, não é viável confeccionar uma checklist com atributos que fazem um Estado possuir maior ou menor capacidade para programar suas políticas. Inúmeros fatores como, por exemplo, as habilidades dos governantes de tomarem decisões de forma centralizada ou de evitarem os vetos às políticas governamentais nas arenas parlamentares ou, ainda, de representarem interesses comuns de determinadas elites - podem afetar positiva ou negativamente o desenvolvimento de determinadas capacidades estatais (Weaver; Rockman, 1993). Por outro lado, apesar das dificuldades de precisão conceitual, argumenta-se que o conceito de capacidades estatais é central na hora de descrever o comprometimento do Estado e seus esforços como um elemento central para a consolidação de democracias estáveis (Carothers, 2002; Fukuyama, 2005). Algo que está diretamente relacionado com o desenvolvimento de políticas públicas mais inclusivas e com a efetiva satisfação das necessidades da população.

Uma perspectiva de análise que vem sendo utilizada para tratar desse conceito é o enfoque multidimensional (Repetto, 2003; Betranou, 2015). Na opinião de Mauricio Cárdenas, existem pelo menos quatro tipos de capacidades estatais que se inter-relacionam. De forma sucinta, pode-se sublinhar que a primeira é a capacidade militar, entendida como a capacidade de o Estado manter a ordem social e superar conflitos que possam alterar o bem-estar e a segurança da sociedade. A segunda é a capacidade burocrática e administrativa, que se refere à profissionalização do aparelho burocrático do Estado e sua aptidão para o cumprimento das atividades cotidianas e emergentes. A terceira é a capacidade fiscal que se relaciona com a habilidade de arrecadação de impostos e tributos. E, finalmente, a quarta é a capacidade de fomentar a qualidade e a coerência das instituições políticas - uma capacidade essencialmente política - garantindo um pleno desenvolvimento do império da lei (Cárdenas, 2010). 
Para fins de organização do presente artigo consideramos capacidades estatais como a aptidão estatal para levar adiante políticas e metas estabelecidas. Frente ao problema de que não necessariamente uma decisão tomada será uma decisão executada (Skocpol; Finegold, 1982), é um conceito que visa destacar as características e procedimentos que o Estado desenvolve visando à obtenção dos resultados propostos.

É importante salientar que o conceito de capacidades estatais traz à tona um ponto importante: instituições não são apenas restrições. Instituições implicam, também, em criar possibilidades de ação (Commons, 1931). Partindo dessa noção básica, mas nem sempre evidente, torna-se mais clara a importância do conceito de capacidade estatal, especialmente em sua dimensão propriamente política, para o estudo das políticas industriais.

Para compreender a importância dessa dimensão na formulação e execução de políticas industriais, é preciso ter em mente o porquê de o Estado e seus agentes terem interesse em promover o desenvolvimento econômico. Segundo Peter Evans (1995), as funções clássicas do Estado dizem respeito a garantir a soberania frente à ameaça de outros Estados e preservar a paz e a ordem interna. Contemporaneamente, porém, o Estado passa, também, a assumir a função de garantir bem-estar à sua população e de promover transformações no sistema econômico, de modo a fomentar a acumulação de capital e a produção de riquezas. Dessa forma, o crescimento econômico passa a ser um requisito para se gerar recursos necessários para atender as demandas sociais por bem-estar (Sicsú; Paula; Michel, 2005).

Contudo, cumprir tais tarefas impõe problemas significativos ao Estado e à sociedade. Quais atividades produtivas fomentar para gerar crescimento econômico e bem-estar? Como construir vantagens comparativas que possibilitem se posicionar mais favoravelmente na hierarquia da divisão internacional do trabalho? Quais os setores estratégicos a serem desenvolvidos? Quais os custos econômicos, sociais e ambientais que a sociedade se dispõe a arcar para alcançar os objetivos nacionais? Como delinear e legitimar esses objetivos?

Como alerta Peter Evans (1995), os caminhos que cada país constrói para resolver os dilemas do seu desenvolvimento dependem da evolução de complexas relações de cooperação e conflito entre as firmas locais e transnacionais, as políticas governamentais e os demais atores sociais interessados no processo. A acumulação de capital e o desenvolvimento econômico são processos intrinsecamente conflituosos, que tendem a gerar desigualdades na apropriação do excedente e a criar interesses contraditórios entre setores sociais diversamente afetados pelos processos de transformação da estrutura produtiva. Assim, promover novas atividades produtivas e conduzir o desenvolvimento exige do Estado significativas capacidades, que vão desde a obtenção de recursos tributários até a construção de uma burocracia coerente, tecnicamente qualificada e fiel. Sobre esse aspecto, é preciso enfatizar que não basta ter objetivos claros; para realizar suas aspirações, os Estados devem contar com as capacidades necessárias. Dentre as capacidades exigidas está a de gerenciar os conflitos inerentes à formulação, à execução e aos impactos das políticas. Ainda, sobre as demandas que a população apresenta ao Estado, essas podem apresentar contradições com os efeitos do crescimento econômico e cabe às instituições de- 
mocráticas processar os conflitos potenciais, oriundos dos interesses diversos, buscando estabelecer consensos mínimos. Mas qual deve ser o desenho dessas instituições? Nesse ponto, entra em jogo o problema informacional crucial para a eficiência das políticas públicas. Se por um lado, determinado nível de centralização decisória é fundamental para se alcançar objetivos globais e interesses nacionais, por outro, a excessiva centralização perde de vista informações e conhecimentos que os atores sociais possuem sobre os contextos específicos em que incidirão as políticas (Rueschemeyer; Evans, 1985; Evans, 1995).

Como resolver essas tendências contraditórias? Basicamente, não há resposta a priori. Porém, é razoável assumir que o pleno desenvolvimento da cidadania é o principal elemento que deve ser considerado ao se pensar nas capacidades e potencialidades dos Estados democráticos levarem adiante as suas políticas. Não à toa enfatiza-se que a grande novidade em termos da organização de novos modelos estatais no século XXI é a expansão do que se convencionou chamar de instituições participativas, isto é, espaços institucionais nos quais existe um poder efetivo de interferência por parte dos cidadãos (Avritzer, 2002; Fung; Wright, 2003; Santos, 2006).

Quando se trata de políticas de desenvolvimento produtivo, Dani Rodrik (2007) argumenta que instituições participativas possibilitam processar e agregar o conhecimento local e as experiências próprias dos agentes na elaboração de novas instituições e políticas. À frente da questão de quais as bases institucionais estariam subjacentes à consolidação de mercados eficientes, existe o problema de como construir essas instituições.

Para dar conta desse problema, as instituições democráticas, dado seu potencial participativo, podem ser consideradas metainstituições capazes de construir boas instituições, baseadas na realidade própria de cada país. Para desenvolver-se, cada sociedade deve buscar suas próprias inovações institucionais, dados os problemas específicos com que se deparam e o aprendizado histórico acumulado. Assim, o debate sobre o desenvolvimento econômico se desloca. Novamente, perde sentido a oposição intervenção X laissez-faire, em prol de um foco no processo de construção institucional (Rodrik, 2007).

Numa direção semelhante, Amartya Sen (2000) enfatiza a importância da participação nas decisões coletivas enquanto uma capacitação, ou seja, como um elemento constitutivo do próprio desenvolvimento, de modo que políticas públicas participativas, em si mesmas, já contribuiriam para esse fim. Também, Joseph Stiglitz (2000) desenvolve o argumento de que experiências de gestão participativas são essenciais para as políticas de desenvolvimento, na medida em que elas favorecem a produção de uma relação mais equilibrada entre o desenvolvimento social e o crescimento econômico (Stiglitz, 2000).

Portanto, a conformação de arenas que possibilitem negociações entre os atores estatais e não-estatais, assim como promovam um intenso fluxo informacional entre Estado e sociedade é fundamental, tendo em vista a formulação de objetivos nacionais e a coordenação de ações durante a implementação de políticas. A institucionalização de tais espaços é importante, também, para fomentar a transparência e o debate público sobre as ações estatais e alinhar as expectativas dos atores econômicos. Em resumo, há significativa 
necessidade de capacidades políticas para promover o desenvolvimento socioeconômico em regimes democráticos.

\section{O histórico das arenas setoriais de negociação tripartite no Brasil}

Desde a década de 1990, a tentativa de consolidar espaços de negociação setorial tripartite em ações voltadas ao desenvolvimento produtivo é encontrada em todos os governos, independente da posição ideológica. A origem desse tipo de arranjo institucional remete a "Nova Política Industrial” do governo José Sarney, no qual, em 1988, instituíram-se câmaras setoriais bipartites, em que participavam governo e empresários, com o objetivo formal de formular diagnósticos e elaborar estratégias para a reestruturação de cadeias produtivas, tendo em vista a identificação de distorções existentes (Anderson, 1997). Na prática, essas câmaras funcionaram como espaços para barganha sobre o controle de preços exercido pelo governo no período, com pouca importância no conjunto da estratégia governamental e sem desenvolver capacidade de coordenação de interesses em torno de uma política industrial que desse novo impulso à economia brasileira (Arbix, 1996).

Já na década de 1990, no governo Fernando Collor de Melo, institui-se os chamados "Grupos Executivos de Política Setorial (GEPS)", dentro do Programa Brasileiro de Qualidade e Produtividade, com o objetivo de promover modernizações setoriais. Os GEPS, a partir do Plano Collor II, lançado em fevereiro de 1991, são transformados em Câmaras Setoriais com o objetivo de negociar a liberação de preços. A novidade nesse caso foi a participação dos trabalhadores na negociação, que passou a ser prevista em lei, a partir da iniciativa parlamentar da oposição. Até o fim de 1992, foram instituídas 29 câmaras setoriais e 135 grupos de trabalho, atuando no âmbito do Ministério da Economia.

Progressivamente, em algumas dessas câmaras, o debate deixou de focar predominantemente na análise de custos e preços e passou-se a discutir políticas de competitividade, com um forte caráter defensivo frente ao cenário de liberalização do comércio exterior. Isso resultou no que se denominou de Acordos Setoriais nas seguintes câmaras: brinquedos; produtos têxteis e de confecções; indústria naval; tratores e máquinas agrícolas; setor automotivo (Anderson, 1997).

Em geral, esses espaços funcionavam como instrumento de pressão do empresariado sobre o governo, operando como "balcões de demandas" (De Toni, 2013, p. 229). Porém, como enfatizado, houve casos em que se fecharam acordos com direcionamentos estratégicos, mesmo que de caráter defensivo. Entre esses casos, o mais significativo foi o do setor automobilístico, que passava por grande crise no período e conseguiu consolidar três acordos entre 1992 a 1995. Esses acordos obtiveram relativo sucesso em atingir as metas propostas sobre produção, vendas, controle de preços, empregos e salários, revertendo, mesmo que temporariamente, a crise do setor (Anderson, 1997). Três elementos se fazem presentes para compreender o nascimento, as dinâmicas e as limitações da câmara automotiva:

I - Os sindicatos aceitaram pactuar com os empresários; os empresários fiz- 
eram concessões econômicas e aceitaram a intromissão dos trabalhadores em assuntos, até então, de sua exclusiva competência; o Estado tomou a iniciativa, propôs a negociação, dispondo-se a compartilhar prerrogativas e a colocar-se como "um igual” na mesa de discussão. [...] II - O funcionamento, a composição, a abrangência e as formas de decisão da câmara do setor automotivo foram construídos a partir da discussão e do acordo consensual entre seus componentes. [...] III - Não por acaso, as três vertentes apontadas, cuja ação extravasou os marcos do corporativismo estatal, enfrentaram oposições de seus próprios pares. Se atentarmos para as fricções constantes entre os coordenadores da economia e os responsáveis pelas câmaras, poderemos observar que as iniciativas voltadas para a formulação da política industrial nem sempre obedeceram a lógica das políticas gerais propostas pelo Estado (Arbix, 1996, p. 28-30).

Historicamente, o processo de industrialização brasileiro teria sido hegemonicamente marcado pela lógica da privatização do Estado, representado pelo acesso privilegiado do empresariado à burocracia estatal, em que a representação dos trabalhadores era deixada de fora ou, no máximo, assumia um papel tutelado nas negociações (Diniz, 2000). A experiência das câmaras setoriais alimentou um debate sobre os potenciais democratizantes desse arranjo. Por um lado, surgia uma interpretação otimista, a qual argumentava sobre o surgimento de um neocorporativismo que implicava em rompimento com padrões autoritários. Também, era percebida uma nova lógica de atuação dos movimentos de trabalhadores, mais afeitos à negociação do que ao conflito, o que foi chamado de "sindicalismo propositivo". Predominaria a busca pela convergência de interesses, o que resultaria em soluções cooperativas ultrapassando dinâmicas de soma zero nas negociações (Arbix, 1996). Por outro lado, esse otimismo foi criticado argumentando-se que as câmaras setoriais, apesar de promover relativo alargamento das negociações, não romperam efetivamente com o padrão autoritário do corporativismo brasileiro. O caráter frágil e fragmentário da estrutura de representação de interesses da sociedade brasileira não deixava garantias de que nas negociações prevaleceria a ótica do interesse público (Diniz, 2000).

Independente da controversa teórica, fato é que, apesar da tentativa de implementação dos governos subsequentes, essas arenas nunca se institucionalizaram de maneira o suficiente para ser possível afirmar que elas foram responsáveis por estruturar novas lógicas de relação entre Estado e sociedade. Também, é preciso ressaltar, que, dentre as várias tentativas posteriores de se concretizar experiências semelhantes, nenhuma obteve o sucesso e a visibilidade da câmara automotiva.

No primeiro governo Fernando Henrique Cardoso (FHC), as experiências das câmaras foram progressivamente deixadas de lado, principalmente, pela resistência da alta burocracia econômica que conduzia o plano de estabilização em realizar qualquer tipo de política industrial (Diniz, 2000). No segundo governo, frente à crise econômica, instituem-se os "Fóruns de Competitividade", buscando-se uma melhor padronização dos procedimentos, de modo a alcançar melhores resultados. Contudo, retoma-se o formato de interlocução bipartite, excluindo das discussões representações dos trabalhadores. Ao que 
tudo indica, as experiências foram de baixo significado prático. Jackson De Toni (2013) identifica que uma das principais diferenças dos arranjos setoriais dos governos Sarney, Collor e Itamar para as experiências que viriam a se constituir após o segundo governo de Cardoso é que, ao contrário das primeiras experiências, os Fóruns de Competitividade de FHC e de Lula não possuíam mandatos legais e competências claramente estabelecidas.

Nesse marco, ainda durante a Política Industrial,Tecnológica e de Comércio Exterior (PITCE), o governo Lula sinaliza dar continuidade aos Fóruns de Competitividade iniciados por Cardoso. Contudo, esses tiveram baixa efetividade, justamente pelo debate sobre a política industrial ter sido canalizado para o âmbito do CNDI. No segundo governo Lula, durante a vigência da Política de Desenvolvimento Produtivo (PDP), tentou-se dar centralidade para esses espaços, mas, novamente, teria sido um objetivo inócuo, predominando na formulação de políticas setoriais uma série de estudos realizados pela Agência Brasileira de Desenvolvimento Industrial (ABDI) (De Toni, 2013). Assim, argumenta-se que

A elaboração e execução da PITCE e da PDP nos governos Lula foram condicionadas, portanto, por um quadro contraditório, do ponto de vista da interlocução com o empresariado industrial e os trabalhadores. Havia uma história de fracassos nas instâncias setoriais [...] e uma intuição generalizada por parte dos empresários que os conselhos e fóruns setoriais se prestavam mais para reforçar o capital político do governo, com baixo poder decisório. O CNDI acabou "compensando" a fragilidade setorial, mesmo que este aspecto não tivesse sido pensado ou planejado pelos burocratas governamentais. Os próprios empresários deixaram de canalizar seu capital político e disposição para participarem das dezenas de fóruns setoriais ao longo do tempo (De Toni, 2013, p. 240-241).

Em síntese, pode-se afirmar que, em geral, a existência de arenas de negociação setorial, na história recente da política industrial brasileira, foi recorrente, porém incapaz de gerar capacidades políticas o suficiente para se elaborar ações que dessem novo impulso à indústria brasileira. Essas arenas apresentaram um histórico de baixa institucionalização, mudando de nome, formato e prerrogativas a cada novo governo, muitas vezes operando de maneira ad hoc, incapaz de coordenar interesses em torno de políticas de longo prazo. Destaca-se, também, que não possuíram um lugar claro na formulação de política econômica, muitas vezes ficando sua operação restrita a setores mais "desenvolvimentistas" da burocracia pública, comprometendo sua eficácia. Ainda, é preciso ressaltar problemas de representatividade, fruto da fragmentação da representação de interesses de empresários e trabalhadores na sociedade brasileira. Isso implicava em conflitos no seio da sociedade civil, os quais, por sua vez, enfraqueciam politicamente os interlocutores frente ao governo. Assim, resulta um histórico de baixa efetividade que alimentou expectativas negativas entre as partes interessadas quanto aos potenciais desses espaços gerarem bons resultados, o que, acaba por enfraquecer a dinâmica de participação e negociação.

Essas características implicam em limitações não desprezíveis para o Estado brasileiro formular e executar políticas industriais, de modo que os fracassos em institucionalizar 
esses espaços impactam a capacidade estatal no curto e no longo prazo. No curto prazo, não se consegue coordenar os agentes no que tange a quantidades produzidas, preços de mercado, políticas salariais, desonerações tributárias e contrapartidas empresariais. Assim, nem mesmo estratégias defensivas são desenhadas para setores em crise. No longo prazo, não se fomenta uma cultura de cooperação e de negociações transparentes, a qual conferiria acúmulo de conhecimento e legitimidade necessários para elaborar estratégias de competitividade que levassem em conta, por exemplo, a definição de investimentos compartilhados em desenvolvimento tecnológico e em treinamento de mão de obra.

\section{Capacidades políticas e os Conselhos de Competitividade do PBM}

O governo Dilma Rousseff, no âmbito do PBM dedicou espaço especial na estrutura de governança para a criação de "Conselhos de Competitividade", de caráter tripartite, reelaborando os canais anteriores de interlocução com a sociedade civil. Seu principal objetivo era elaborar um conjunto de Agendas Setoriais de política industrial. Esses conselhos, de caráter consultivo, teriam por atribuição realizar diagnósticos da situação atual e das perspectivas futuras dos sistemas produtivos e, assim, contribuir na elaboração e implementação dessas Agendas Setoriais, as quais designariam uma série de políticas verticais, estruturantes do PBM. Ainda, deveriam ser o espaço em que seriam sugeridas e negociadas as contrapartidas empresariais para a consecução das metas do PBM. Além do processo de formulação, essas arenas se reuniriam para monitorar e avaliar as políticas implementadas. Segundo o regimento, as reuniões deveriam ocorrer de três em três meses, podendo ainda ser convocadas reuniões extraordinárias pelos coordenadores durante o período de vigência do PBM (2011-2014).

Sobre os conselhos de competitividade do PBM, um primeiro aspecto a enfatizar é a disposição governamental de abrir esses espaços de diálogo tripartite e conceder-lhes uma função clara na estrutura de governança da política. Essa estrutura seria configurada pela existência de um Comitê Executivo para cada cadeia de valor específica. Esse Comitê seria formado por funcionários de diversos órgãos governamentais que deveriam formular e implementar uma agenda de trabalhos setoriais. Os membros desses comitês seriam integrantes dos Conselhos Setoriais, espaços onde operaria negociações e trocas de informações com empresários e trabalhadores a respeito dos objetivos da política. Uma vez definidos esses objetivos, seriam repassados pelo gestor do comitê para o Grupo Executivo do PBM, encarregado de articular e consolidar programas e ações setoriais, estruturados com as Coordenações Sistêmicas, responsáveis por políticas horizontais.

$\mathrm{Na}$ composição dos Conselhos de Competitividade estariam os funcionários governamentais que compõem os Comitês Executivos do PBM e, no máximo, 15 representantes da sociedade civil, indicados pelo Ministério do Desenvolvimento Indústria e Comércio (MDIC), aprovados pelo Grupo Executivo do PBM.Também, para as reuniões 
poderiam ser convidados consultores técnicos. A secretaria dos conselhos ficaria sob a responsabilidade da ABDI.

Frente ao histórico em que as arenas setoriais tripartites possuíam um funcionamento ad hoc, sem muita visibilidade ou transparência, essa definição clara da estrutura de governança por si só indica um melhor planejamento e a intenção de dar maior efetividade a esses espaços, dentro da estratégia governamental de consolidação de apoio político. Outro elemento importante a ser destacado é que, ao contrário das experiências anteriores, sobre as quais é dificil obter informações, na página da internet do PBM, era possível acessar o regimento, a composição e as atas da maioria das reuniões, sendo esse um indicativo de transparência da política.

Contudo, um melhor planejamento não foi o suficiente para romper com o histórico de baixa institucionalização e com a descrença dos agentes na efetividade desses espaços em fomentar políticas de longo prazo que transformem a estrutura produtiva e impulsionem a competitividade da indústria brasileira. O primeiro elemento empírico que confirma esse aspecto é que apenas um conselho se reuniu em 2011. Na maior parte dos conselhos as primeiras reuniões se realizaram somente em 2012. Ainda, dos 19 conselhos de competitividade, quatro se reuniram apenas em 2012; 15 conselhos se reuniram em 2012 e em 2013; no ano de 2014, somente três conselhos realizaram reuniões (Tabela 1).

Resulta que, em média, ao longo dos quatro anos, cada conselho se reuniu apenas cinco vezes. A média de reuniões em 2012 foi de 3,3; em 2013, foi de 1,7 e, em 2014, foi de 0,2 . Apenas dez conselhos fizeram cinco reuniões ou mais. Três conselhos não realizaram mais do que três reuniões, e seis não se reuniram mais do que quatro vezes (Tabela 1). Dado que a periodicidade prevista no estatuto era de reuniões trimestrais, ou seja, quatro reuniões anuais, esses dados também expressam o baixo dinamismo desses espaços, em que predominou a realização de encontros durante a fase de formulação da política, sem dar continuidade em etapas posteriores de monitoramento e avaliação.

Tabela 1- Número de Reuniões dos Conselhos de Competitividade

\begin{tabular}{cccccc}
\hline Conselho de Competitividade & 2011 & 2012 & 2013 & 2014 & Total \\
Defesa, Aeronáutica e Espacial & 0 & 3 & 4 & 1 & 7 \\
TIC/Complexo Eletrônico & 0 & 6 & 1 & 0 & 7 \\
Serviços Logísticos & 0 & 3 & 4 & 0 & 7 \\
Serviços & 0 & 3 & 4 & 0 & 7 \\
Comércio & 0 & 3 & 4 & 0 & 7 \\
Química & 0 & 4 & 2 & 0 & 6 \\
Mineração & 0 & 4 & 2 & 0 & 6 \\
Móveis & 0 & 3 & 2 & 0 & 5 \\
Higiene Pessoal, Perfumaria e Cosméticos & 0 & 4 & 1 & 1 & 5 \\
Complexo da Saúde & 1 & 2 & 3 & 0 & 5 \\
Petróleo, Gás e Naval & 0 & 3 & 1 & 0 & 4
\end{tabular}




$\begin{array}{cccccc}\text { Bens de Capital } & 0 & 3 & 1 & 1 & 4 \\ \text { Couro, Calçado, Têxtil e Con- } & & & & & \\ \text { fecções, Gemas e Joias } & 0 & 3 & 1 & 0 & 4 \\ \text { Automotivo } & 0 & 4 & 0 & 0 & 4 \\ \text { Construção Civil } & 0 & 3 & 1 & 0 & 4 \\ \text { Agroindústria } & 0 & 3 & 1 & 0 & 4 \\ \text { Energias Renováveis } & 0 & 3 & 0 & 0 & 3 \\ \text { Metalurgia } & 0 & 3 & 0 & 0 & 3 \\ \text { Celulose e Papel } & 0 & 3 & 0 & 0 & 3 \\ \text { Total } & 1 & 63 & 32 & 3 & 95 \\ \text { Média } & 0,1 & 3,3 & 1,7 & 0,2 & 5,0\end{array}$

Fonte: Queiroz-Stein, 2016.

Como explicado na introdução, foram escolhidos dois casos para analisar com maior profundidade a dinâmica desses conselhos. O primeiro conselho de competitividade a ser analisado é o de Defesa, Aeronáutica e Espacial, o qual realizou três reuniões em 2012 e quatro em 2013, disponibilizando as atas dessas reuniões no site do PBM, todas tendo como pauta principal as Agendas Setoriais, tanto em sua fase de construção, durante o ano de 2012, quanto de monitoramento em 2013.

Sobre a participação nesse conselho, um primeiro aspecto que chama a atenção é que, ao contabilizar todos os nomes que aparecem nas atas, chegamos ao número de 129 pessoas que participaram de pelo menos uma reunião. Outro fato a salientar é que, dentre os conselheiros originalmente indicados, dez não participaram de nenhuma reunião, sendo que, entre esses, seis eram representantes governamentais e quatro empresariais. Contudo, isso não significa que houve baixa participação.

Pelo contrário, em média, cada reunião teve a participação de 39 pessoas; 24 conselheiros estiveram presentes em mais de $50 \%$ das reuniões e 12 participaram em mais de $70 \%$ das reuniões. É importante salientar que dessas 24 pessoas, 12 não estavam na lista de conselheiros originalmente designados, sendo 2 representantes empresariais e os outros 10 representantes governamentais. Ou seja, ao longo do processo, algumas pessoas "assumiram a frente", mesmo que de maneira informal. Dentre os que foram originalmente designados conselheiros, também ocorreu uma substituição dos titulares pelos suplentes; quatro dos que estiveram presentes em mais de 50\% das reuniões eram, originalmente, suplentes (Tabela 6).

Dessa forma, pode-se ponderar que, mesmo havendo adesão em termos de número de participantes, o prestígio do espaço é questionável, o que se expressa tanto na alta presença de suplentes, quanto nas participações informais. Outro fato interessante é que o coordenador original, Murilo Marques Barboza, então secretário de Produtos de Defesa do Ministério da Defesa (MD), só participou de uma reunião; na prática, quem coordenou as atividades foi Maria Luisa Campos Machado Leal, da ABDI, que era para ser a vice-coordenadora. Ela esteve presente em todas as reuniões; os outros dois conselheiros 
que participaram de todas as reuniões foram Edmilson Rogério de Oliveira, representante da Confederação Nacional dos Metalúrgicos (CNM/CUT), e o Coronel Hilton Grossi, do MD, o qual, por sinal, não estava na lista original de conselheiros.

Sobre a representatividade do conselho, a composição original sem contabilizar os suplentes, era de 15,79\% de representantes dos trabalhadores, 31,58\% de representantes empresariais e 52,63\% de representantes governamentais (Gráfico 1). Observando esses percentuais para as 129 pessoas que participaram de pelo menos uma reunião, encontra-se o seguinte resultado: 4,65\% de trabalhadores, 30,23\% de empresários e $65,12 \%$ do governo (Gráfico 2). Assim, já é visível como, na prática, ocorre perda de representatividade dos trabalhadores. Quando se realiza o mesmo cálculo apenas para os 24 integrantes que se fizeram presentes em mais de $50 \%$ das reuniões, eleva-se ainda mais a representatividade governamental, chegando a 79,17\%; aqui, quem mais perde é a representatividade empresarial que passa para $16,67 \%$, enquanto a de trabalhadores se mantém relativamente constante em 4,17\% (Gráfico 3).

Gráfico 1- Composição Original do CCDAE

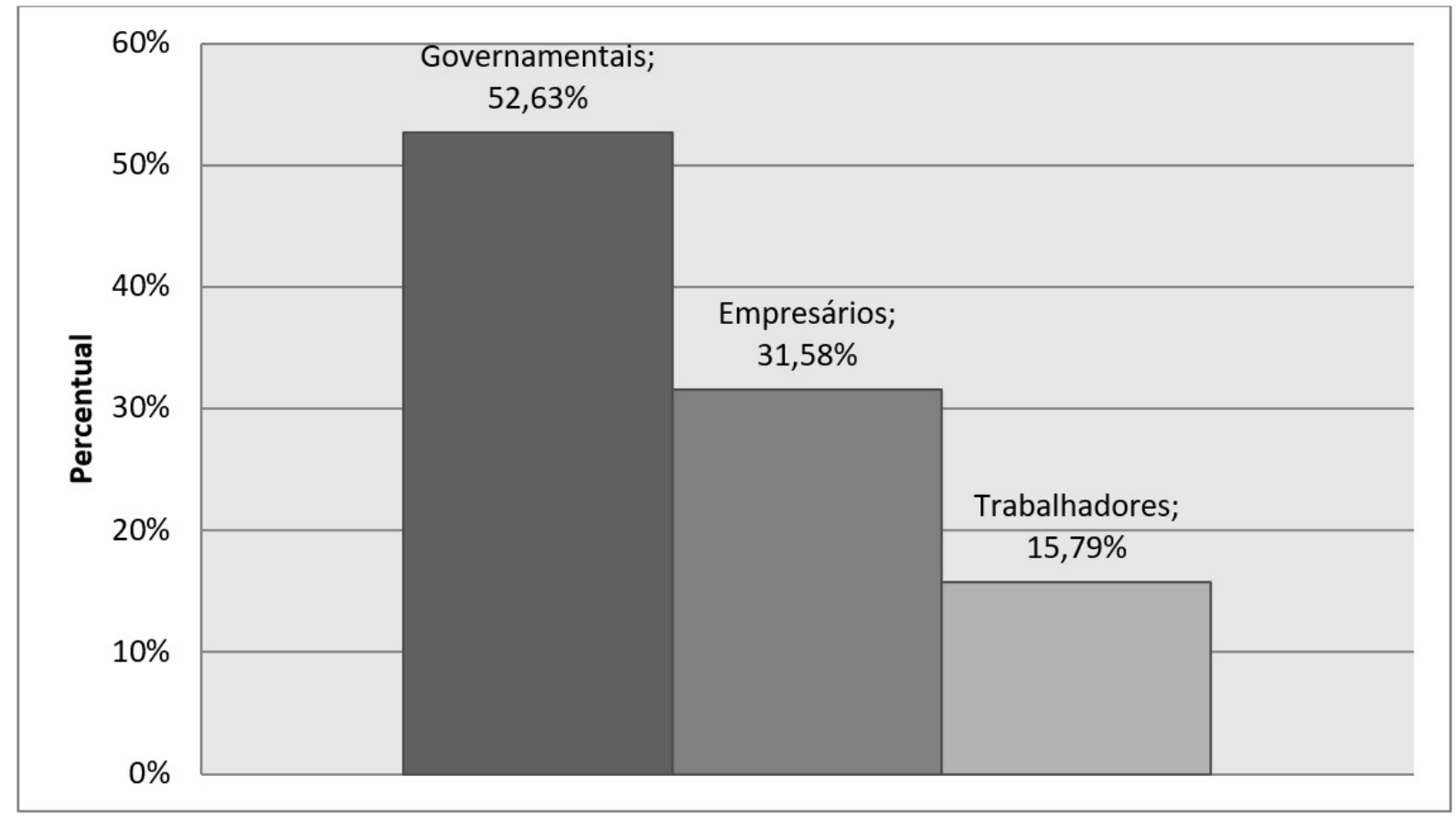

Fonte: Elaboração própria com base nas atas do Conselho (2015). 
Gráfico 2 - Participação em no Mínimo uma Reunião do CCDAE

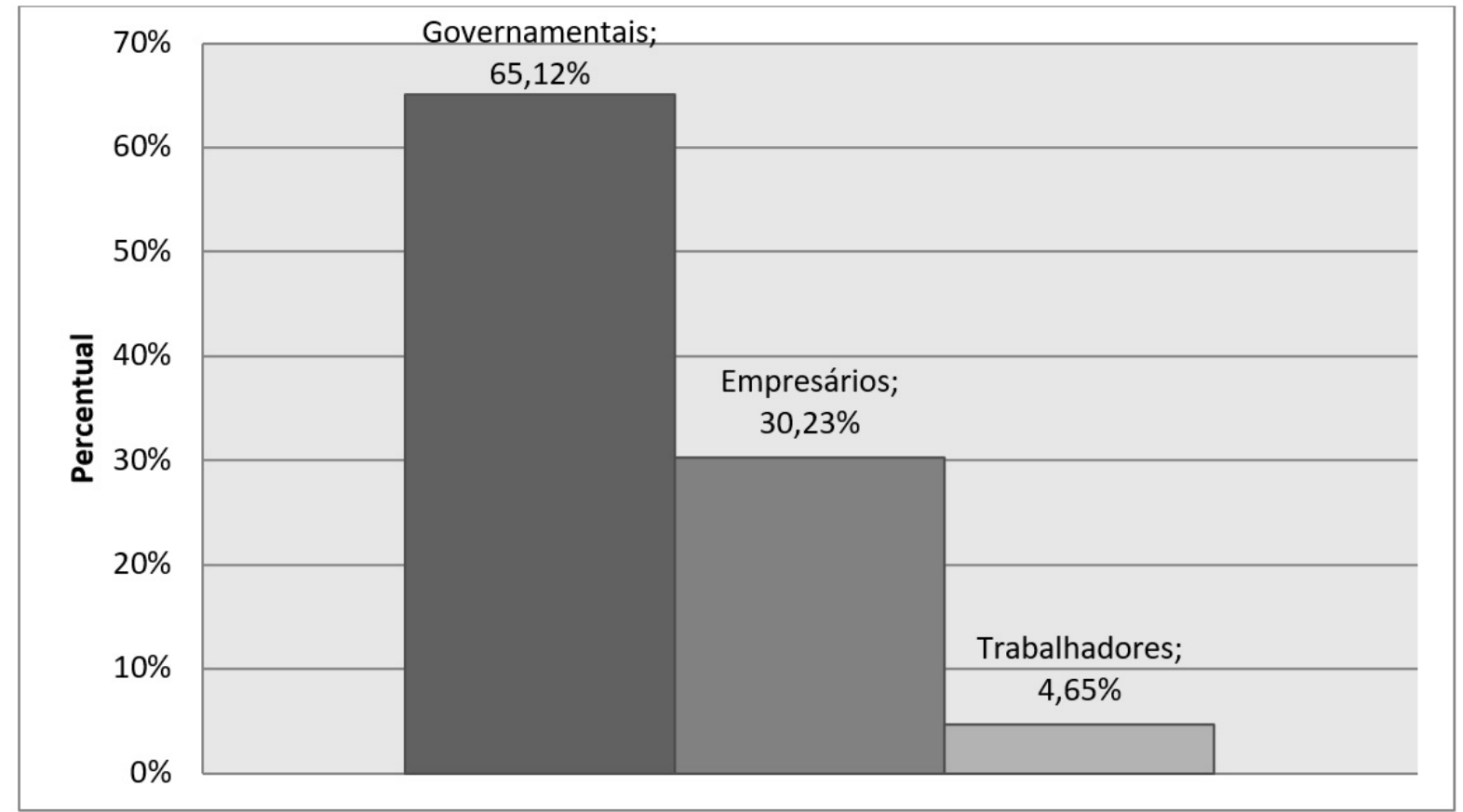

Fonte: Elaboração própria com base nas atas do Conselho (2015).

Gráfico 3 - Participação em Mais de 50\% das Reuniões do CCDAE

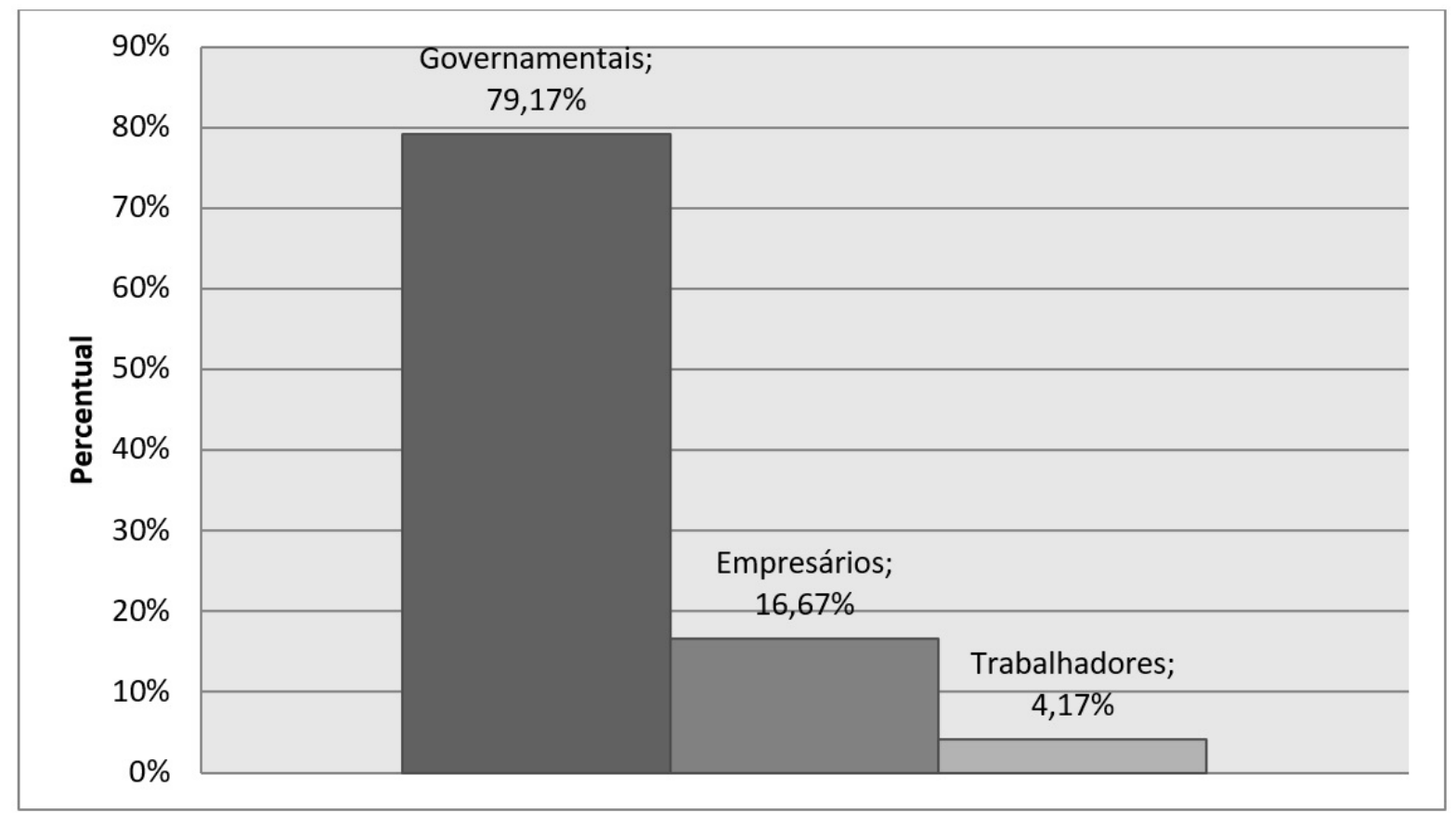

Fonte: Elaboração própria com base nas atas do Conselho (2015).

Dentre os 19 representantes governamentais que participaram de mais de 50\% das reuniões (Tabela 2), nenhum era Ministro de Estado. Os participantes com cargos mais altos dentro de seus órgãos eram, no máximo, diretores, como, por exemplo, a própria Maria Luisa Leal, que no período era Diretora de Desenvolvimento Tecnológico e Inovação da ABDI, ou militares com alta patente de oficiais, como o Coronel da Força Aérea 
Brasileira, Ancelmo Modesti ou o General de Divisão do Exército Brasileiro, Aderico Mattioli. Vale salientar que o Presidente da ABDI, Mauro Borges Lemos, participou de duas reuniões durante o ano de 2013.

Tabela 2 - Participantes em mais de 50\% das reuniões do CCDAE

\begin{tabular}{|c|c|c|c|c|c|}
\hline Nome & Entidade & Função & Setor & Total & $\%$ \\
\hline $\begin{array}{l}\text { Maria Luisa Cam- } \\
\text { pos Machado Leal }\end{array}$ & ABDI & $\begin{array}{l}\text { Vice-Coor- } \\
\text { denadora }\end{array}$ & Governo & 7 & $100 \%$ \\
\hline Edmilson Rogério de Oliveira & $\begin{array}{l}\text { CNM/ } \\
\text { CUT }\end{array}$ & Titular & $\begin{array}{l}\text { Trabalha- } \\
\text { dores }\end{array}$ & 7 & $100 \%$ \\
\hline Cel. Hilton Grossi & MD & Não Original & Governo & 7 & $100 \%$ \\
\hline Walter Bartels & AIAB & Titular & Empresários & 6 & $86 \%$ \\
\hline Cláudio Ferreira da Silva & ABDI & Não Original & Governo & 6 & $86 \%$ \\
\hline Larissa de Freitas Querino & ABDI & Titular & Governo & 5 & $71 \%$ \\
\hline $\begin{array}{l}\text { Cynthia Araújo Nas- } \\
\text { cimento Mattos }\end{array}$ & ABDI & Suplente & Governo & 5 & $71 \%$ \\
\hline $\begin{array}{l}\text { Sérgio Leite Schmi- } \\
\text { tt Correa Filho }\end{array}$ & BNDES & Titular & Governo & 5 & $71 \%$ \\
\hline Karen Leal & ABDI & Não Original & Governo & 5 & $71 \%$ \\
\hline Paulus Vinícius da Rocha Fonseca & BNDES & Não Original & Governo & 5 & $71 \%$ \\
\hline Lourenço Drummond & ABIMDE & Não Original & Empresários & 5 & $71 \%$ \\
\hline Yu Chi Au & $\mathrm{AEB}$ & Suplente & Governo & 4 & $57 \%$ \\
\hline Cel. R1 Ancelmo Modesti & EMAER & Suplente & Governo & 4 & $57 \%$ \\
\hline Gen. Div. Aderico Mattioli & MD & Titular & Governo & 4 & $57 \%$ \\
\hline Aloysio Novais de Carvalho Silva & MPOG & Suplente & Governo & 4 & $57 \%$ \\
\hline Robinson Vladenir Botelho Lucas & $\mathrm{SAC} / \mathrm{PR}$ & Titular & Governo & 4 & $57 \%$ \\
\hline João Emílio Padovani Gonçalves & $\mathrm{CNI}$ & Titular & Empresários & 4 & $57 \%$ \\
\hline Carlos Duek & $\mathrm{SAE} / \mathrm{PR}$ & Não Original & Governo & 4 & $57 \%$ \\
\hline João Valentim Bin & AEB & Não Original & Governo & 4 & $57 \%$ \\
\hline Rodrigo Barbosa & MDIC & Não Original & Governo & 4 & $57 \%$ \\
\hline Fernanda Bocorny Messias & ABDI & Não Original & Governo & 4 & $57 \%$ \\
\hline José Serrador Neto & $\begin{array}{c}\text { EM- } \\
\text { BRAER }\end{array}$ & Não Original & Empresários & 4 & $57 \%$ \\
\hline Jose Zeno Fontana & FINEP & Não Original & Governo & 4 & $57 \%$ \\
\hline Marlos Agostini & MCTI & Não Original & Governo & 4 & $57 \%$ \\
\hline
\end{tabular}

Fonte: Elaboração própria com base nas atas das reuniões (2015).

Apenas um representante dos trabalhadores estava entre aqueles que participaram em mais de 50\% das reuniões no caso, o representante da CNM/CUT, Edmilson Rogério de Oliveira, que no período era funcionário da EMBRAER e presidente do Sindicato Aeroes- 
pacial de São Paulo (Tabela 6). Dada a preocupação com a representatividade dos participantes, é preciso salientar que, no período, a legitimidade dessa entidade em representar os trabalhadores estava sendo questionada judicialmente pelo Sindicato dos Metalúrgicos de São José dos Campos e Região, pertencente à central CSP/Conlutas, e por outras entidades.

Dentre as 24 pessoas que participaram em mais de $50 \%$ das reuniões, quatro eram representantes empresariais. O mais assíduo foi Walter Bartels, que, desde 1997, é presidente da Associação das Indústrias Aeroespaciais do Brasil (AIAB). Dentre as associadas da AIAB estão as principais firmas brasileiras e estrangeiras que atuam no setor, incluindo a EMBRAER, a AKAER, a HELIBRAS, dentre outras.

O segundo representante empresarial mais assíduo foi Lourenço Drummond, diretor de Relações Institucionais da Associação Brasileira das Indústrias de Materiais de Defesa e Segurança (ABIMDE), a qual possui uma lista significativa de entidades associadas, incluindo órgãos relacionados às forças armadas, empresas nacionais e empresas estrangeiras. Nota-se que não participava das reuniões o então presidente da ABIMDE, Orlando José Ferreira Neto. Também não houve participação em nenhuma reunião de Sami Youssef Hassuani, que já havia sido designado como conselheiro titular no conselho setorial enquanto presidente da AVIBRAS e se tornou presidente da ABIMDE em 2013.

Os outros dois representantes empresariais com significativa participação foram João Emílio Padovani Gonçalves, gerente executivo de Política Industrial da CNI e José Serrador Neto, gerente de relações governamentais da EMBRAER, os quais cumpriam o papel técnico designado por sua função. Portanto, em relação à representatividade empresarial, o único conselheiro titular que expressava algum elemento de liderança política em seu setor e participou com frequência do CCDAE foi Walter Bartels. Dessa forma, o nível de representatividade de trabalhadores e empresários do CCDAE foi baixo. Houve uma predominância de participação de atores governamentais, sendo que nenhum deles era ministro de Estado.

O funcionamento do CCDAE, ao que tudo indica, comprimiu o objetivo de promover trocas informacionais entre os atores. A leitura das atas possibilita inferir em geral, não se verificou predominância de fala de apenas um setor. Empresários e representantes de trabalhadores possuíam seus "comentários/sugestões" citados nas atas recorrentemente. O mesmo é observável entre os diversos órgãos governamentais. Os debates focalizaram diversos aspectos como as diretrizes estratégicas para as cadeias produtivas, os instrumentos utilizados, a definição de metas, as fontes de financiamento, as políticas de incentivo às exportações, a necessidade de fomentar as MPEs do setor, as fronteiras tecnológicas etc.

O fluxo de informações também foi importante ao se discutir três pontos que se destacaram pela sua recorrência: a utilização de compras governamentais para fomentar o setor; o déficit de mão de obra qualificada; o financiamento ao investimento, exportações e inovações das empresas da Base Industrial de Defesa. Contudo, todos esses temas já vinham sendo enfatizados em outros documentos da política industrial brasileira, lançados pela ABDI, como no "Diagnóstico da Base Industrial de Defesa Brasileira", lançado em março de 2011, e no "Panorama da Base Industrial de Defesa: Segmento Aeroespacial", 
lançado em 2013. Ou seja, a predominância governamental no conselho fazia-se valer na agenda de debates que delimitava o escopo dessas trocas informacionais.

Também, identificam-se restrições na promoção de coordenação de ações e interesses. Por exemplo, nas reuniões ocorridas em 2013, em que o principal objetivo era monitorar o andamento das agendas setoriais, os participantes foram divididos em grupos de trabalho, em que os representantes da sociedade civil possuíam papel ativo. Tendo em vista que o principal objetivo dos Conselhos de Competitividade era delimitar as Agendas Estratégicas Setoriais, nesses grupos realizaram-se uma série de tarefas como melhorar o detalhamento de ações, rever a redação da agenda, consultar terceiros sobre informações pertinentes e construir cronogramas. Assim, é possível considerar que o CCDAE promoveu alguma coordenação entre os participantes, mas em um nível bastante elementar da formulação e do monitoramento da política.

Ao analisar quais medidas foram efetivamente incluídas na Agenda Estratégica Setorial percebe-se que as questões do financiamento e das compras governamentais foram contempladas no "Programa de Financiamento para Empresas Estratégicas de Defesa", na "Política Nacional de Compensação Tecnológica, Industrial e Comercial (Offset)" e na criação do Núcleo de Promoção Comercial do MD. Contudo, vale mencionar com maior atenção o tema da qualificação da mão de obra, o qual pode ser compreendido como significativamente estratégico, por ser um fator crítico para essa indústria. $\mathrm{O}$ " $\mathrm{Pa}-$ norama da Base Industrial de Defesa: Segmento Aeroespacial” já alertava que:

Mesmo que venham a existir recursos financeiros para apoiar todos os programas de aquisição e P\&D requeridos pelo Poder Aeroespacial, é bastante possível que venhamos a ter dificuldades ou mesmo experimentar fracassos na indústria devido ao apagão de mão de obra especializada. Embora profissionais de várias formações sejam necessários ao esforço de concepção, desenvolvimento e produção de sistemas aeroespaciais e de defesa, estamos aqui fazendo referência explícita à falta de engenheiros e de técnicos especializados para a condução dos trabalhos requeridos (ABDI, 2011, p.56).

A despeito de ser crucial, o tema da qualificação da mão de obra não obteve qualquer referência na formulação final das Agendas Setoriais. Isso ocorreu mesmo verificando-se que, como consta na ata das reuniões ocorridas nos dias 13 e 14 de junho de 2013, ocorreu o encaminhamento de uma proposta formulada pela CNM/CUT especificamente centrada nessa questão, a qual seria levada para avaliação na ABDI. Dessa forma, pode-se concluir que esse encaminhamento não foi efetivado, o que provavelmente reflete justamente os problemas de representação percebidos nessa arena os quais comprometiam sua capacidade política.

O Conselho de Competitividade do Setor Químico (CCQ) realizou quatro reuniões em 2012 e duas em 2013. Cada reunião teve, em média, a participação de 24 pessoas, ou seja, foram muito mais enxutas do que as reuniões do CCDAE, que possuíam em média 39 participantes. Também foi significativamente menor o total de nomes que constam em ata: 73 neste conselho, contra os 129 encontrados no conselho anteriormente analisado. 
Sobre a adesão ao conselho, observou-se que 24 pessoas participaram em mais de $50 \%$ das reuniões. Dessas 24 pessoas, nove não estavam listadas originalmente como conselheiros. Assim, novamente há uma adesão informal que pode indicar que conselheiros originais enviaram substitutos, os quais não eram previstos nem mesmo como suplentes. Adiciona-se a isso o fato de que, entre os 28 indicados originalmente como conselheiros, seis não participaram de nenhuma reunião, incluindo três representantes empresariais. Portanto, no CCQ também parece haver problemas de prestígio: há adesão as reuniões, mas não daquelas pessoas originalmente indicadas. Um indicativo disso está na ata da primeira reunião do Comitê Executivo do setor Químico. Mesmo que o Comitê Executivo fosse um espaço em que se previa apenas a presença de agentes governamentais, para essa primeira reunião, foram convidados dois representantes da sociedade civil, Fernando Figueiredo, da Associação Brasileira da Indústria Química (ABIQUIM), e José Ricardo Roriz Coelho, presidente da Associação Brasileira da Indústria do Plástico (ABIPLAST), ambos indicados como conselheiros titulares no CCQ. $\mathrm{Na}$ ata dessa reunião consta: "A discussão ganhou corpo e as entidades revelaram diferenças significativas de opinião, com a ABIQUIM aceitando mais facilmente discutir questões de longo prazo e a ABIPLAST refratária ao tema, pois crê haver muito a fazer no curto prazo sobre o padrão regulatório brasileiro" (Ata, 2012, p. 2). O que se verifica posteriormente é que Roriz Coelho só participa das duas primeiras reuniões do conselho. Nas subsequentes, é substituído por Milene Tessarin, economista da entidade, que participa de três reuniões.

Tabela 3 - Participantes em mais de 50\% das reuniões do CCQ

\begin{tabular}{|c|c|c|c|c|c|}
\hline Nome & Entidade & Função & Setor & Total & $\%$ \\
\hline Gabriel Lourenço Gomes & BNDES & $\begin{array}{l}\text { Coorde- } \\
\text { nadora }\end{array}$ & Governo & 6 & $100,00 \%$ \\
\hline Fernando Figueiredo & ABIQUIM & Titular & Empresários & 6 & $100,00 \%$ \\
\hline Júnia Casadei Lima Motta & ABDI & Titular & Governo & 5 & $83,33 \%$ \\
\hline Carlos Alberto Itaparica & $\mathrm{CNQ} / \mathrm{CUT}$ & Titular & $\begin{array}{c}\text { Trabalha- } \\
\text { dores }\end{array}$ & 5 & $83,33 \%$ \\
\hline $\begin{array}{l}\text { Martim Francisco de } \\
\text { Oliveira e Silva }\end{array}$ & BNDES & $\begin{array}{l}\text { Não Ori- } \\
\text { ginal }\end{array}$ & Governo & 5 & $83,33 \%$ \\
\hline $\begin{array}{l}\text { Symone Christine } \\
\text { de Santana Araújo }\end{array}$ & MME & Titular & Governo & 4 & $66,67 \%$ \\
\hline Antenor Eiji Nakamura & $\mathrm{CNQ} / \mathrm{CUT}$ & Titular & $\begin{array}{c}\text { Trabalha- } \\
\text { dores }\end{array}$ & 4 & $66,67 \%$ \\
\hline Rodolfo Villela Marino & $\begin{array}{c}\text { GRUPO } \\
\text { ELEKEIROZ }\end{array}$ & Titular & Empresários & 4 & $66,67 \%$ \\
\hline Reinaldo Schroeder & UGT & Titular & $\begin{array}{l}\text { Trabalha- } \\
\text { dores }\end{array}$ & 4 & $66,67 \%$ \\
\hline $\begin{array}{l}\text { Alexandre Ribei- } \\
\text { ro Pareira Lopes }\end{array}$ & MDIC & $\begin{array}{l}\text { Não Ori- } \\
\text { ginal }\end{array}$ & Governo & 4 & $66,67 \%$ \\
\hline
\end{tabular}




\begin{tabular}{|c|c|c|c|c|c|}
\hline Carlos Lima & ABDI & $\begin{array}{l}\text { Não Ori- } \\
\text { ginal }\end{array}$ & Governo & 4 & $66,67 \%$ \\
\hline Marilene Teixeira & CNQ/CUT & $\begin{array}{l}\text { Não Ori- } \\
\text { ginal }\end{array}$ & $\begin{array}{l}\text { Trabalha- } \\
\text { dores }\end{array}$ & 4 & $66,67 \%$ \\
\hline Fátima G. C. Ferreira & ABIQUIM & $\begin{array}{l}\text { Não Ori- } \\
\text { ginal }\end{array}$ & Empresários & 4 & $66,67 \%$ \\
\hline Marcos A. de Marchi & $\begin{array}{l}\text { ABIQUIM/ELE- } \\
\text { QUEIROZ }\end{array}$ & $\begin{array}{l}\text { Não Ori- } \\
\text { ginal }\end{array}$ & Empresários & 4 & $66,67 \%$ \\
\hline Ana Sofia Brito Peixoto & ABDI & Suplente & Governo & 3 & $50,00 \%$ \\
\hline $\begin{array}{c}\text { Adelaide Maria de } \\
\text { Souza Antunes }\end{array}$ & INPI & Titular & Governo & 3 & $50,00 \%$ \\
\hline $\begin{array}{l}\text { José Eduardo Cin- } \\
\text { tra de Oliveira }\end{array}$ & ABRAFAS & Titular & Empresários & 3 & $50,00 \%$ \\
\hline Marcelo Lyra & BRASKEM & Titular & Empresários & 3 & $50,00 \%$ \\
\hline Frederico A. Turra & CNI & Titular & Empresários & 3 & $50,00 \%$ \\
\hline Herbert Passos Filho & $\begin{array}{l}\text { FORÇA SIN- } \\
\text { DICAL }\end{array}$ & Titular & $\begin{array}{l}\text { Trabalha- } \\
\text { dores }\end{array}$ & 3 & $50,00 \%$ \\
\hline Henri Armand Slezynger & $\begin{array}{l}\text { UNIGEL/ } \\
\text { ABIQUIM }\end{array}$ & Titular & Empresários & 3 & $50,00 \%$ \\
\hline Ernesto Carrara Júnior & MPOG & $\begin{array}{l}\text { Não Ori- } \\
\text { ginal }\end{array}$ & Governo & 3 & $50,00 \%$ \\
\hline Denis Oshima Roberto & DIEESE & $\begin{array}{l}\text { Não Ori- } \\
\text { ginal }\end{array}$ & $\begin{array}{l}\text { Trabalha- } \\
\text { dores }\end{array}$ & 3 & $50,00 \%$ \\
\hline Milene Tessarin & ABIPLAST & $\begin{array}{l}\text { Não Ori- } \\
\text { ginal }\end{array}$ & Empresários & 3 & $50,00 \%$ \\
\hline
\end{tabular}

Fonte: Elaboração própria com base nas atas das reuniões (2015).

Se por um lado há esse problema de prestígio, por outro, verifica-se no CCQ o fato de que, entre aqueles que estiveram presentes em mais de 50\% das reuniões, há uma distribuição mais equilibrada entre os diferentes setores representados: 37,5\% eram representantes governamentais e 37,5\% eram representantes empresariais; $25 \%$ eram representantes dos trabalhadores (Gráfico 3). A título comparativo, ressalta-se que essa é uma diferença em relação ao CCDAE, no qual 79,17\% dos que participaram em mais de $50 \%$ das reuniões eram representantes governamentais. Esses dados indicam que, mesmo havendo os problemas antes expostos, os representantes da sociedade civil tiveram uma maior participação, o que pode ter contribuído para o CCQ ter cumprido tido maior representatividade, pelo menos em comparação com seu homólogo, o CCDAE. 
Gráfico 4 - Composição Original do CCQ

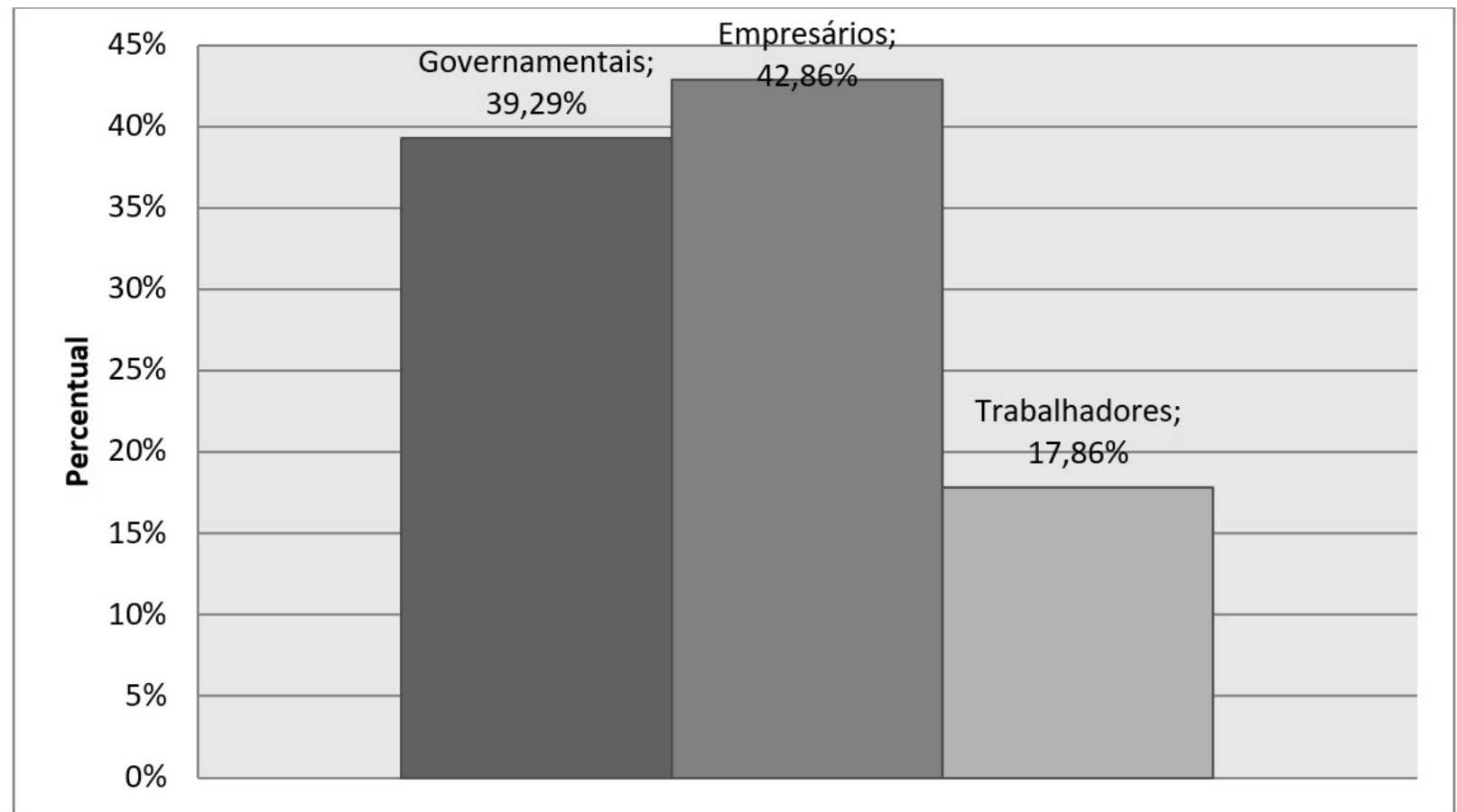

Fonte: Elaboração própria com base nas atas das reuniões (2015).

Gráfico 5 - Participação em no Mínimo uma Reunião do CCQ

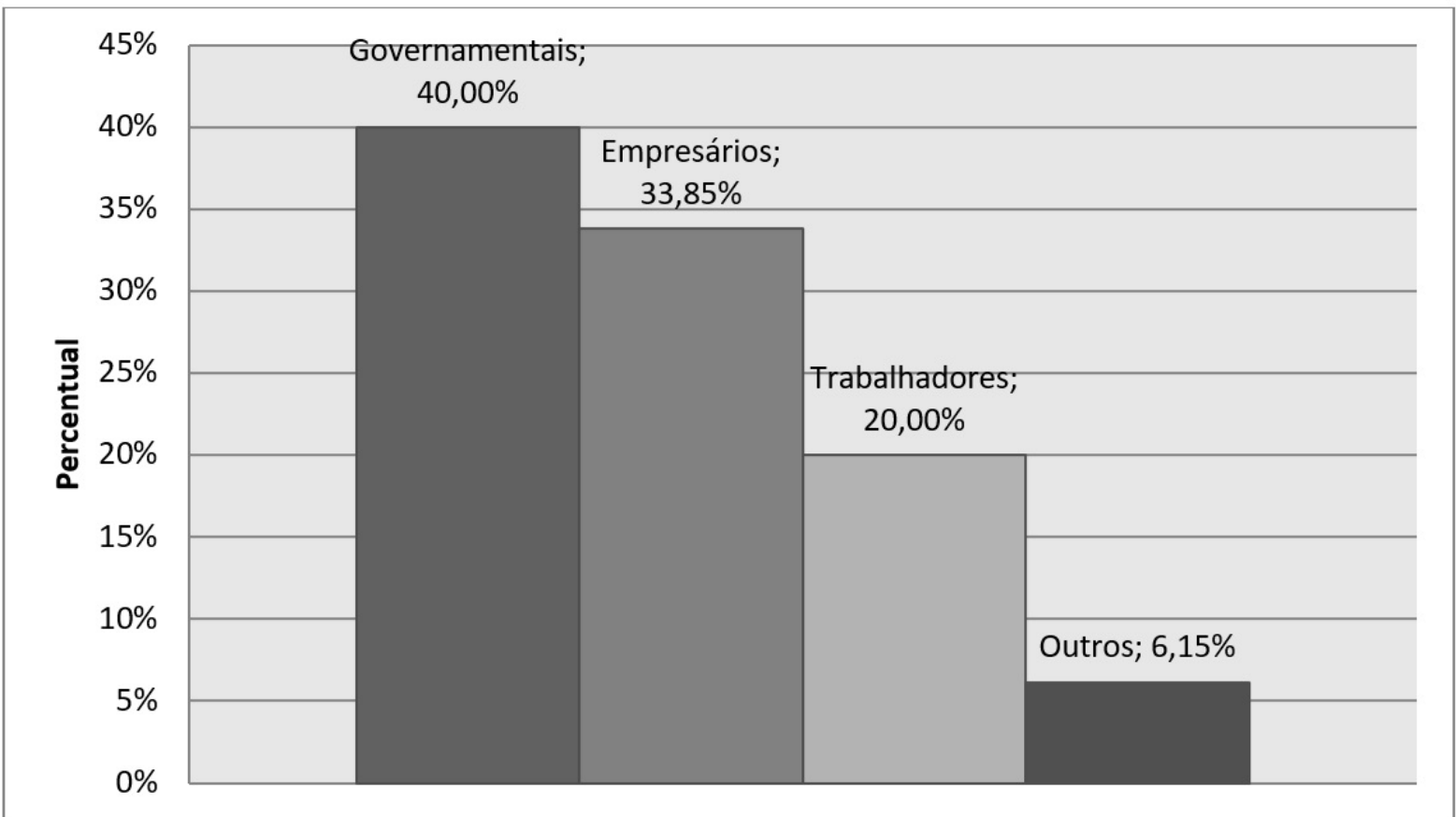

Fonte: Elaboração própria com base nas atas das reuniões (2015). 
Gráfico 6 - Participação em mais de 50\% das Reuniões do CCQ

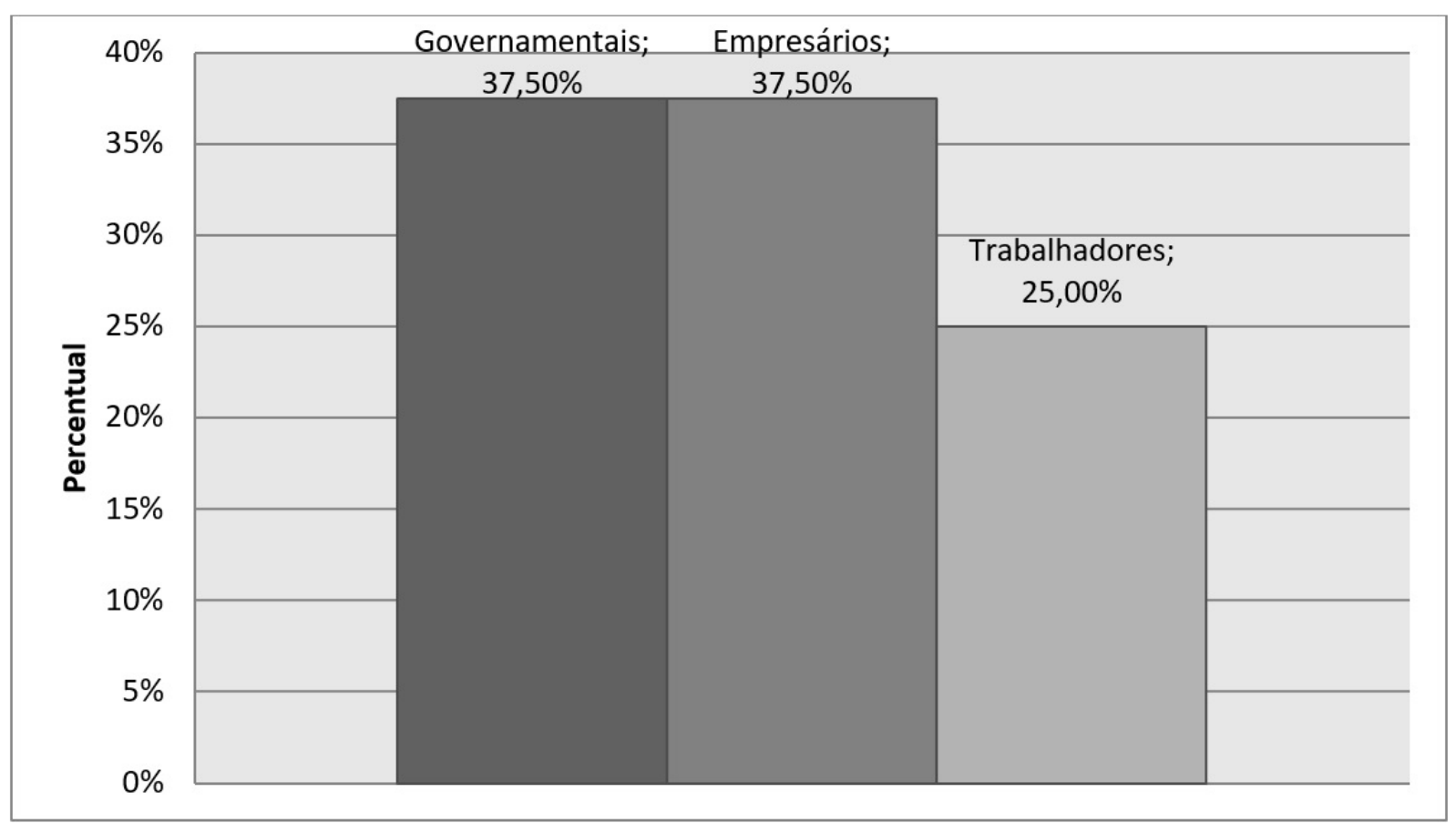

Fonte: Elaboração própria com base nas atas das reuniões (2015).

Outro aspecto observado é que, na prática, a participação dos trabalhadores se eleva. $\mathrm{Na}$ composição original, previa-se que 17,86\% dos conselheiros seriam representantes desse segmento, 39,39\% representantes governamentais e 42,86\% representantes empresariais (Gráfico 4). Quando se computa os dados daqueles que participaram de pelo menos uma reunião, chega-se ao seguinte resultado: 20\% de trabalhadores, 40\% para o governo e 33,85\% para empresários (Gráfico 5). Ao se observar apenas aquelas pessoas que participaram de mais de $50 \%$ das reuniões, como antes descrito, o percentual dos trabalhadores eleva-se em 5\% e os percentuais de representantes governamentais e os de empresários se igualam em 37,5\% (Gráfico 6).

Sobre os representantes governamentais, no CCQ também não se verifica a presença de membros dos altos escalões governamentais, com envergadura e peso político. Esse fato foi alvo de reivindicação de representantes da sociedade civil. Como consta na Ata da primeira reunião do Comitê Executivo do Setor Químico, ocorrida nos dias 01 e 02 de fevereiro de 2012:

Avançados na elaboração do Diagnóstico e da Agenda Setorial, o Comitê convidou dois representantes do setor privado para um primeiro olhar sobre o que havia sido discutido até então. Os convidados foram os senhores Fernando Figueiredo (Presidente da ABIQUIM) e José Ricardo Roriz Coelho (Presidente da ABIPLAST). Já no início a ABIQUIM questionou a ausência do Ministério da Fazenda, alegando que o poder de decisão está naquele órgão. A opinião foi acompanhada pela ABIPLAST. A resposta foi dada pelo BNDES que apresentou a estrutura de governança do PBM e apontou os pontos no fluxo de decisão onde o MF estará presente. As discussões em torno da questão amenizaram e caminhou-se para a apresentação do Diagnóstico e da Agenda Setorial (Ata, 2012, p. 2). 
Porém, há de se salientar que o coordenador do CCQ, Gabriel Lourenço Gomes, o qual participou de todas as reuniões, era no período Chefe do Departamento de Indústria Química do BNDES, ou seja, ocupava um cargo com poder decisório. Outro aspecto a enfatizar é a alta qualificação técnica de alguns dos representantes governamentais que participaram mais ativamente. O próprio coordenador é doutor em Planejamento Energético. Também verificou-se a participação em três reuniões de Adelaide Maria de Souza Antunes, professora aposentada da Universidade Federal do Rio de Janeiro, doutora em Engenharia Química, analista sênior do INPI, especializada na indústria petroquímica, conselheira da ABIQUIM; e a participação, em cinco reuniões, de Martim Francisco de Oliveira e Silva, Engenheiro Civil, Doutor em Administração de Empresas, professor da PUC-RJ e técnico do BNDES, atuando, há bastante tempo, no Departamento de Indústria Química dessa instituição.

Em relação à representação empresarial, é preciso destacar a atuação da ABQUIM. Fernando Figueiredo, então presidente da ABIQUIM, a mais antiga associação do setor, foi o único conselheiro representante da sociedade civil que participou de $100 \%$ das reuniões. Ainda, um dado significativo é que três das seis reuniões foram realizadas na própria sede da ABIQUIM, o que simboliza a adesão e a importância do conselho para essa entidade.

Outra figura de peso que participou do conselho de competitividade do setor químico, mais especificamente de quatro reuniões, foi Rodolfo Villela Marino, então chairman da Elekeiroz S.A, uma das maiores empresas do setor. Rodolfo é membro da família Villela, a qual, junto com a família Setubal, dirige o holding Itaúsa - Investimentos Itaú S.A. - que em 2014 possuía um patrimônio líquido de $\mathrm{R} \$ 36,4$ bilhões e era controlador daquele que, então, era o maior banco privado da América Latina, o Itaú Unibanco (Itaúsa registra..., 2014). A importância desse conselheiro se expressa no fato de ser um dos 12 componentes do Conselho Familiar que administra a Itaúsa e decide sobre seus investimentos mais importantes, sendo, dessa forma uma ligação direta entre esse grupo, com alto poder financeiro, e o governo, mediada por um espaço aberto e transparente.

Outros representantes empresariais que participaram em mais de 50\% das reuniões foram Henri Slezynger, presidente da Unigel S.A. e conselheiro da ABIQUIM; Marcelo Lyra, Vice-Presidente de Relações Institucionais da Brasken S.A. e José Eduardo Cintra de Oliveira, diretor executivo da Associação Brasileira de Produtores de Fibras Artificiais e Sintéticas. Portanto, sobre a representatividade empresarial, pode-se afirmar que, apesar da ausência do conselheiro e presidente da ABLIPAST, o CCQ contou com a participação de lideranças políticas do setor e de pessoas com capacidade de tomada de decisões em postos estratégicos.

Em relação aos representantes dos trabalhadores, o que se percebe é que o CCQ conseguiu englobar as duas grandes confederações do setor e três centrais sindicais, além de contar com pessoas que atuam no movimento sindical de estados em que o setor químico é desenvolvido, de modo a ocorrer um relativo equilíbrio no aspecto regional da representação. Carlos Itaparica e Antenor Nakamura, representantes da Confederação Nacional do Ramo Químico (CNQ) e da CUT, participaram, respectivamente, de cinco 
e quatro reuniões. Reinaldo Schroeder, que participou de quatro reuniões, representava a União Geral dos Trabalhadores e era presidente do Sindicato dos Plásticos de Joinville, filiado à Confederação Nacional dos Trabalhadores no Ramo Químico (CNTQ). Herbert Passos Filho participou de três reuniões e era Presidente do Sindicato dos Trabalhadores nas Indústrias Químicas, Farmacêuticas e de Fertilizantes da Baixada Santista, $1^{\circ}$ Vice-Presidente da Federação dos Trabalhadores das Indústrias Químicas e ocupava cargos de direção nacional na Força Sindical.

Portanto, pode-se afirmar que o CCQ obteve representatividade, tanto de empresários quanto de trabalhadores. Os representantes governamentais não contaram com figuras de envergadura política, mas verificou-se alta qualificação técnica. Além disso, destaca-se que houve uma participação efetiva da sociedade civil no conselho.

Observando as dinâmicas de trocas informacionais, nas atas das reuniões, é possível perceber que o CCQ não foi apenas um espaço de anúncio de medidas governamentais. Em todas as reuniões verifica-se a participação de empresários e trabalhadores no sentido de discutir as proposições governamentais, apresentar suas críticas, diagnósticos e sugestões de políticas, além de fazer reivindicações ao governo. Ainda, na leitura das atas, fica claro que o CCQ, junto com o comitê executivo da indústria química, foi um espaço no qual se discutiu propostas e se dividiu trabalho entre os órgãos governamentais e os representes da sociedade civil, de modo a aprimorar as propostas da agenda estratégica.

Um exemplo mais claro de troca informacional e de como o conselho possibilitou a coordenação dos agentes ocorreu no caso da proposta de reduzir custos de matérias primas e de fomentar o gás natural como matéria prima para produção de ureia e amônia, os quais são insumos para indústria de fertilizantes. Para tanto, conformou-se um grupo de trabalho com representantes da ABIQUIM, Ministério de Minas e Energia, PETROBRÁS, BNDES, ABDI e MDIC que atuou realizando estudos e formalizando propostas, as quais são efetivadas no item da Agenda Estratégica que trata do objetivo de reduzir custos de matéria prima, com especial atenção ao papel do gás natural.

Outros exemplos de como as temáticas discutidas no CCQ efetivaram em políticas encontram-se na proposta do Regime Especial de Incentivo ao Investimento na Indústria Química (REPEQUIM), no Regime Especial de Incentivo ao Desenvolvimento de Infraestrutura da Indústria de Fertilizantes (REIF), na desoneração do PIS/CONFINS para a cadeia petroquímica e no Regime Especial de Incentivo à Inovação na Indústria Química (REIQ-Inovação). Ou seja, pode-se considerar como um espaço que, mesmo possuindo alguns problemas em relação à participação e à representatividade, promoveu a troca informacional, a coordenação dos agentes e foi efetivo em propor políticas. Provavelmente, a alta capacidade técnica dos conselheiros e a forte adesão de uma das associações empresariais mais importantes do setor, a ABQUIM, favoreceram esses resultados.

Assim, comparando os dois conselhos pode-se afirmar que ambos enfrentaram problemas de prestígio, contando com um número significativo de ausências de conselheiros e de presença de suplentes ou de participantes informais. Entretanto, há diferenças na participação nos dois conselhos. Enquanto no CCDAE ocorreu uma clara predominância governa- 
mental e havia baixa presença de lideranças representativas da sociedade civil, a participação no CCQ obteve um maior equilíbrio entre empresários, trabalhadores e governo, bem como contava com uma representatividade mais ampla. No que se refere à participação governamental, em ambos não se verificou a presença de ministros de Estado, sendo que a ausência de lideranças políticas chegou a ser fato questionado pelos participantes.

Em comparação com o CCQ, o CCDAE apresentou trocas informacionais menos intensas e uma coordenação em níveis mais básicos. Provavelmente, isso é reflexo da menor participação de empresários e trabalhadores nesse espaço. Por sua vez, não por um acaso houve diferenças em termos de efetividade. Enquanto no CCQ ocorreu a proposição de ações para uma ampla medida de problemas, no CCDAE não se verificou a inclusão na Agenda Estratégica de um ponto fundamental: a oferta de mão de obra. Ainda, é preciso salientar que tanto no CCQ, quanto no CCDAE, não se avançou em um dos objetivos centrais que o governo possuía ao estabelecer essas arenas de diálogo que era negociar contrapartidas empresariais aos incentivos governamentais.

\section{Conclusões}

Neste artigo, para analisar o arranjo institucional da política industrial brasileira mobilizamos o conceito de capacidade política, em sua dimensão participativa, no período 2011-2014. Nossas conclusões tendem a se alinhar a outros estudos que identificaram uma associação entre as baixas capacidades institucionais, o perfil e os resultados do PBM (Shapiro, 2013; Queiroz-Stein; Herrlein Jr., 2016).

É preciso salientar que esse arranjo já apresentava uma baixa capacidade política em sua dimensão participativa, o que se expressava no fracasso em reativar o CNDI e no fato de o CDES ter se enfraquecido e deixado de ser um lócus de discussão de política industrial, no período estudado (Queiroz-Stein, 2016; 2017). Pode-se afirmar que os Conselhos de Competitividade do PBM não conseguiram reverter esse quadro. Primeiro, por apresentaram, em geral, um baixo dinamismo, o que se expressa no fato de que, em média, durante os quatro anos, foram realizadas cinco reuniões por cada conselho, o que fica bem aquém da previsão estatutária de serem realizadas com periodicidade trimestral. Segundo, é verificado que 12 conselhos realizaram um número de reuniões menor ou igual à média. Terceiro, há uma concentração de reuniões no ano de 2012. O PBM foi concebido e apresentado à sociedade em 2011, dessa forma é dificil considerar que esses conselhos atuaram na fase de formulação da política. Assim, operaram no máximo como uma forma de consulta para agendas que já vinham sendo delineadas pelo governo. Ainda, é preciso considerar que nos anos de 2013 e 2014, quando poderia se realizar o monitoramento e a avaliação, há uma queda substancial no número de reuniões realizadas.

Há de se salientar que, comparando com as experiências históricas, se percebe que em sua estruturação e funcionamento, os Conselhos de Competitividade do PBM apresentaram algumas inovações, especialmente possuindo funções mais claras na estrutura 
de governança das políticas e maior transparência, possibilitando um acesso facilitado às informações. Contudo, na análise mais minuciosa do CCDAE e do CCQ, verificou-se a reprodução de alguns padrões negativos, especialmente no que se refere a problemas de representatividade, os quais são reflexos de uma estrutura fragmentada de organização dos interesses na sociedade brasileira, e de efetividade, no sentido de dar encaminhamento às deliberações e negociar contrapartidas empresariais aos incentivos governamentais. A falta de efetividade pode ter por fatores explicativos tanto os déficits de representatividade, que implicam em menor poder político dos agentes da sociedade civil, quanto à ausência de participação dos altos escalões governamentais, com capacidade de tomar decisões.

Esses problemas reforçam expectativas negativas dos agentes quanto à possibilidade de funcionamento dessas arenas. Por sua vez, essas expectativas negativas contribuem para o baixo dinamismo desses espaços. Gera-se, assim, um ciclo vicioso, no qual, mesmo depois de três décadas de tentativa, esse tipo de arranjo teve pouco efeito em consolidar um tipo de política industrial que desse novo impulso competitivo à estrutura produtiva nacional.

É preciso ressaltar que a ausência dessas capacidades traz implicações para o tipo de política industrial implementada. Há baixa capacidade de coordenação dos atores no curto e no longo prazo. Não se formula acordos em tornos de estratégias que alavanquem a competitividade no longo prazo. Não são definidas com clareza quais serão as contrapartidas empresariais aos incentivos fiscais, nem a forma de monitorar o cumprimento e de aplicar punições em caso de descumprimento. Também não se gera o conhecimento e a legitimidade necessários para formulação de políticas, as quais deveriam ser aperfeiçoadas no longo prazo, contando com um aprendizado coletivo, para o qual é totalmente necessário o monitoramento e avaliação contínuos das políticas. Acima de tudo, a ausência desses elementos implica em uma política industrial pouco transparente, sujeita a pressões particularistas e inócua no objetivo de promover um desenvolvimento socioeconômico sustentável.

\section{Referências}

ABDI.Agência Brasileira de Desenvolvimento Industrial. Panorama da Base Industrial de Defesa: Segmento Aeroespacial. ABDI: Brasília, 2011.

ANDERSON, Patrícia. A Política Industrial no Brasil e a Experiência das Câmaras Setoriais na Década de 90.1997. 106 f. Dissertação (Mestrado) - Universidade Federal do Rio Grande do Sul, Porto Alegre, 1997.

ARBIX, Glauco. Uma Aposta no Futuro: Os Primeiros Anos da Câmara Setorial da Indústria Automobilística. São Paulo: Scritta, 1996.

AVRITZER, Leonardo. Democracy and the Public Space in Latin America. Princeton: Princenton University Press, 2002.

BETRANOU, Julián. Capacidad Estatal: Revision del Concepto y Algunos Ejes de Análisis y Debate. Revista Estado y Políticas Públicas, n. 4, p 37-59, 2015.

CÁRDENAS, Mauricio. State Capacity in Latin America. Washington: Brookings Institution, 2010.

CAROTHERS, Thomas. The End of the Transition Paradigm. Journal of Democracy, v. 13, n. 1, p. 5-21, 2002. 
CINGOLANI, Luciana. The State of State Capacity: a review of concepts, evidence and measures. UNUMERIT Working Paper Series, Maastricht University, 2013-053, p.1-52. Disponível em: < http://digitalarchive. maastrichtuniversity.nl/fedora/get/guid:25cb727f-2280-41f0-a1da-ecf3ac48230f/ASSET1>. Acesso em: 31 out. 2017.

COMMONS, John Rogers. Institutional Economics. American Economic Review, v. 21, p. 648-657, 1931.

DE TONI, Jackson. Novos Arranjos Institucionais na Política Industrial do Governo Lula: a força das novas ideias e dos empreendedores políticos. 2013. 390 f. Tese (Doutorado em Ciência Política) - Programa de Pós-Graduação em Ciência Política, Universidade Federal de Brasília, Brasília, 2013.

Uma Nova Governança no Padrão de Relacionamento Público-privado na Política Industrial Brasileira. Revista de Sociologia e Política, Curitiba, v. 23, n. 55, p. 97-117, set. 2015.

DINIZ, Eli. A Busca de um Novo Modelo Econômico: padrões alternativos de articulação público-privado. Rev. Sociol. Polít., Curitiba, v. 14, p. 7-28, jun. 2000.

EVANS, Peter. Embedded Autonomy: Sates and industrial transformation. Princeton: Princeton University Press, 1995.

FUKUYAMA, Francis. Stateness First. Journal of Democracy, v. 16, n. 1, p. 84-88, 2005.

FUNG, Archon;WRIGHT, Erik Olin. Deepening Democracy: institutional innovations in empowered participatory governance. London:Verso, 2003.

GOMIDE,Alexandre; PIRES, Roberto. Capacidades estatais e democracia: a abordagem dos arranjos institucionais de políticas públicas. In: GOMIDE, A. D. Á.; PIRES, R. R. C. Capacidades estatais e democracia: arranjos institucionais de políticas públicas. Brasília: IPEA, 2014. p. 365.

ITAÚSA registra lucro consolidado de $\mathrm{R} \$ 1,784$ bilhão no $1^{\circ}$ trimestre. G1, São Paulo, 6 maio 2014. Economia, Negócios. Disponível em:< http://g1.globo.com/economia/negocios/noticia/2014/05/itausa-registra-lucroconsolidado-de-r-1784-bilhao-no-1-trimestre.html>. Acesso em: 12 jul. 2015.

QUEIROZ-STEIN, Guilherme de. Arranjo Institucional de Políticas Públicas e Capacidades Políticas: Proposta de Índice para Ilustrar a Evolução das Capacidades nas Políticas Industriais Brasileiras no séc. XXI. In:JOVEN, G. D. P. A. América Latina em Foco: Novas Perspectivas de Análise sobre a Região. Montevidéo: Alacip, 2017.

Política industrial no século XXI: capacidades estatais e a experiência brasileira (2003-2014). 2016. 159 f. Dissertação (Mestrado em Ciência Política) - Instituto de Filosofia e Ciências Humanas, Universidade Federal do Rio Grande do Sul, Porto Alegre, 2016. ___ _ HERRLEIN JR., Ronaldo. Política Industrial no Brasil: uma Análise das Estratégias Propostas nas Experiências Recentes, 2003-2014. Planejamento e Políticas Públicas Planejamento e Políticas Públicas, n. 47, dez. 2016.

REPETTO, Fabián. Capacidad estatal: requisito necesario para una mejor política social en América Latina. VIII Congreso internacional del CLAD, Panamá, p. 28-31, out. 2003.

RODRIK, Dani. One economics, many recipes: globalization, institutions and economic growth. Princeton: Princeton University Press, 2007.

RUESCHEMEYER, Dietrich; EVANS, Peter. The State and economic transformation: toward an analysis of the conditions underlying effective intervention. In: EVANS, P.; RUESCHEMEYER, D.; SKOCPOL, T. Bring the State Back In. New York: Cambridge University Press, 1985.

SANTOS, Boaventura de Souza. A reinvenção Solidária e Participativa do Estado. In: SANTOS, B. D. S. $A$ gramática do Tempo: para uma nova cultura política. São Paulo: Cortez, 2006. p. 341-76.

SEN, Amartya. Desenvolvimento como liberdade. Rio de Janeiro: Companhia das Letras, 2000.

SHAPIRO, Mario Gomes. Ativismo estatal e industrialismo defensivo: instrumentos e capacidades na política industrial brasileira. IPEA, Rio de Janeiro, 2013 (Texto para Discussão 1856).

SICSÚ, João; DE PAULA, Luiz Fernando; MICHEL, Renalt. Novo-desenvolvimentismo: um projeto nacional de crescimento com equidade social. Rio de Janeiro: Fundação Konrad Adnauer, 2005. 
SKOCPOL, Theda; FINEGOLD, Kenneth. State Capacity and Economic Intervention in the Early New Deal. Political Science Quarterly, v. 97, n. 2, p. 255-278, 1982.

STIGLITZ, Joseph. Participación y Desarrollo: Perspectivas desde el Paradigma Integral del Desarrollo. Revista Instituciones y Desarrollo, Barcelona, n. 7, p. 93-120, 2000.

WEAVER, Kent; ROCKMAN, Bert. Assessing the Effects of Institutions. In: Do institutions matter? Washington: The Brookings Institutions, 1993. p. 2-26. 


\title{
Institutional Arrangement, State Capacity and Industrial Policy: the Competitiveness Councils of Plano Brasil Maior
}

\begin{abstract}
In this article, it is discussed the relationship between the state capacities and the industrial policy, from an institutional arrangements of public policies perspective. Empirically, it is analyzed the historical experience of tripartite sectoral councils' implementation and the case of the Competitiveness Councils of "Plano Brasil Maior". The conclusions indicate that the Competitiveness Councils reproduced problems that were find in the previous experience and they were incapable of generate enough capacities to coordinate the agents, aiming the councils functions.
\end{abstract}

Keywords: state capacities, institutional arrangements, public policies, industrial policies, tripartite sectoral councils.

\section{Arreglo institucional, pericias estatales y política industrial:los consejos de competitividad del Plano Brasil Maior}

\section{Resumen}

En este artículo, se discute la relación entre las pericias estatales y la política industrial, desde la perspectiva del análisis de los arreglos institucionales de las políticas públicas. Como objeto empírico, se analiza la experiencia histórica de la implementación de los consejos sectoriales tripartitos en la política industrial de Brasil y el caso de los Consejos de Competitividad del "Plano Brasil Maior". Los resultados indican que los Consejos de Competitividad han reproducido problemas encontrados en experiencias anteriores y no fueron hábiles para generar acciones suficientes para coordinar a los actores conforme era requerido por su función.

Palabras clave: pericias estatales, arreglos institucionales, políticas públicas, política industrial, consejos sectoriales tripartitos. 